\title{
UMNO-PAS Islamization Policy Under The Leadership of Abdullah Badawi and Najib Razak
}

\section{Dasar Islamisasi Politik UMNO dan PAS pada Era Abdullah Badawi dan Najib Razak}

\author{
Muhamad Helmy Sabtu ${ }^{1 *}$, Amalin Sabiha Ismail ${ }^{1}$, Khairul Azman Mohamad \\ Suhaimy ${ }^{1}$
}

${ }^{1}$ Jabatan Sains Sosial, Pusat Pengajian Umum dan Kokurikulum,

Universiti Tun Hussein Onn Malaysia, Parit Raja, Batu Pahat, Johor, MALAYSIA

*Corresponding Author

DOI: https://doi.org/10.30880/jstard.2020.02.03.011

Received 30 September 2020; Accepted 30 November 2020; Available online 31 December 2020

\begin{abstract}
Political Islamization in Malaysia is represented by the two largest Malay-Muslim party, UMNO and PAS. This article analyzes the Islamization policy introduced and implemented by UMNO and PAS during the era of Abdullah Badawi and Najib Razak as Prime Minister of Malaysia. This research presented four policies implemented by UMNO; Islam Hadhari, the Wasatiyyah principle, the Shariah Indeks of Malaysia, and the cooperation between UMNO and PAS. The four principles of Islamization introduced by PAS include; the agenda of the Islamic State, the implementation of Hudud, the Islam democratization, and the concept of Welfare State. The proposing of Islamization policies by both parties clearly shows that Islam has been one of the key indicators of country governance. The study also found that UMNO-PAS's Islamization policy has finally pioneering the cooperation between two parties from 2015 until now.
\end{abstract}

Keywords: Political Islamization, UMNO, PAS, Muafakat Nasional

\begin{abstract}
Abstrak: Islamisasi politik di Malaysia diwakili oleh dua parti Melayu-Islam terbesar, UMNO dan PAS. Artikel ini menganalisis dasar Islamisasi yang diperkenalkan dan dilaksanakan oleh UMNO dan PAS pada era Abdullah Badawi dan Najib Razak sebagai Perdana Menteri Malaysia. Penyelidikan ini mengemukakan empat dasar yang dilaksanakan oleh UMNO; Islam Hadhari, prinsip Wasatiyyah, Indeks Syariah Malaysia, dan kerjasama antara UMNO dan PAS. Empat prinsip Islamisasi yang diperkenalkan oleh PAS meliputi; agenda Negara Islam, pelaksanaan Hudud, pendemokrasian Islam, dan konsep Negara Berkebajikan. Usulan dasar Islamisasi oleh keduadua pihak jelas menunjukkan bahawa Islam telah menjadi salah satu petunjuk utama pemerintahan negara. Kajian itu juga mendapati bahawa dasar Islamisasi UMNO-PAS akhirnya memelopori kerjasama antara dua pihak dari tahun 2015 hingga sekarang.
\end{abstract}

Kata Kunci: Islamisasi politik, UMNO, PAS, Muafakat Nasional 


\section{Pengenalan}

Malaysia merupakan sebuah negara bermajoriti Islam. UMNO (United Malays National Organisation) dan PAS (Parti Islam Se-Malaysia) merupakan dua parti politik Melayu-Islam yang dominan di Malaysia. Dalam lanskap politik dan demokrasi, UMNO dan PAS memperkenalkan Islam politik dalam kerangka yang berbeza. UMNO melihat perlaksanaan Islam perlu diadun dengan acuan pembangunan dan pemodenan negara. Sementara PAS melihat Islam perlu ditegakkan dengan melaksanakan hukum-hakam dan perundangan yang telah digariskan oleh Al-Quran dan AsSunnah. Bagaimanapun, kedua-dua parti berdepan dengan dilema dan persimpangan iaitu untuk mendapatkan sokongan dan undi dari Melayu yang merupakan rakyat majoriti, namun dalam masa yang sama Malaysia dilatari dengan kepelbagaian etnik, sosiobudaya dan agama yang bersifat rencam.

Sebelum mengadakan kerjasama bermula tahun 2015 sehingga membentuk pakatan politik Muafakat Nasional pada tahun 2019, kedua-dua parti UMNO dan PAS merupakan rival di antara satu dengan yang lain. Persaingan kuasa di antara dua parti dominan Melayu-Islam ini dapat dilihat melalui pengenalan dasar Islamisasi bagi memperoleh sokongan masyarakat serta meneruskan kelangsungan politik. Di sebalik dasar-dasar Islamisasi yang diperkenalkan, timbul persoalan apakah bentuk dasar yang ditawarkan oleh kedua-dua parti Islam dominan ini bagi memenangi masyarakat dan mengangkat nilai Islam di Malaysia? Dari persoalan tersebut, maka artikel ini akan merungkaikan bentuk dasar Islamisasi yang diperkenalkan oleh UMNO dan PAS di Malaysia khususnya sepanjang era pentadbiran Abdullah Badawi dan Najib Razak sebagai Perdana Menteri.

\section{Latar Belakang Islamisasi UMNO dan PAS}

Pengukuhan dasar Islamisasi UMNO dan PAS mengalami beberapa siri evolusi yang bersifat rencam. Secara harfiahnya, dasar Islamisasi UMNO hanya bermula pada tahun 1981 setelah Mahathir Mohamed (1981 hingga 2003) mengambil tampuk pentadbiran negara daripada Hussein Onn (1976 hingga 1981). Pemerintahan Mahathir telah membuka ruang seluas-luasnya kepada program Islamisasi di Malaysia berdasarkan kepada dua faktor bersifat luaran dan dalaman.

Dari sudut faktor luaran, penggagasan dasar Islamisasi di Malaysia bermula selepas tercetusnya Revolusi Iran pada tahun 1978. Revolusi sosial yang berlaku di Iran berpunca daripada keperluan pentadbiran Mohamad Reza Pahlavi (turut dikenali sebagai Shah Iran) (1941 hingga 1979) untuk menjalankan modenisasi sosial bagi membentuk masyarakat yang berpelajaran, sekular dan bersifat kebaratan (westernized society). Bagi mencapai misi pemodenan sosial, maka segala pengaruh dan peranan agamawan perlu dikurangkan atau dihapuskan sama sekali. Akibatnya, kepercayaan masyarakat tradisonal Iran yang berpegang teguh kepada ajaran Islam sudah mula dicairkan identiti keislamannya bagi mencapai matlamat pemodenan masyarakat bersifat anti-Islam. Justeru, Ayatollah Khomeini secara lantang mengkritik dasar anti-Islam Shah Iran sehingga ia membawa kepada revolusi massa untuk menggulingkan rejim autoritarian Shah Reza (Gurbuz 2003: 114-115). Rentetan daripada berlakunya Revolusi Iran, maka pengaruh dan semangat revolusi telah merebak ke seluruh dunia termasuklah ke Malaysia sehinggakan masyarakat mendesak kerajaan untuk mula mewujudkan dasar-dasar Islamisasi bagi mengukuhkan pegangan Islam di Malaysia.

Kejayaan Iran dan kepimpinan ulama Khomeini menjatuhkan kerajaan sekular Pahlavi turut memberikan kesan terhadap PAS sebagai parti Islam. Yusuf Rawa yang menggantikan Mohd Asri sebagai presiden telah melaksanakan penstrukturan semula parti. Dua pembaharuan utama yang telah dilaksanakan adalah dari aspek struktural dan ideologikal. Dari aspek struktural, kepimpinan ulama telah diperkenalkan dengan golongan berkenaan diberikan autoriti yang lebih tinggi dalam parti. Majlis Syura Ulama diperkenalkan sebagai badan pemutus tertinggi parti dengan diketuai oleh seorang Mursyidul Am (Badlilhisham \& Napisah, 2011). Manakala dari aspek ideologikal, PAS beralih kepada ideologi Islamisme dengan memperkenalkan matlamat perlaksanaan undang-undang Syariah (hudud) dan agenda negara Islam. Bagi mencapai matlamat ini, PAS menggunakan pendekatan radikalisme agama dengan mengisytiharkan parti berkenaan merupakan satu-satunya parti yang memperjuangkan Islam dan matlamat negara Islam. Menerusi ucapan kontroversi yang dikenali sebagai 'Amanat Haji Hadi', Abdul Hadi menyatakan bahawa pihak yang tidak bersama PAS adalah kafir dan merupakan musuh Islam. Slogan jihad dilaungkan oleh PAS bagi menentang kerajaan UMNO-BN yang dianggap sekular. PAS turut menentang dasar Islamisasi yang dilaksanakan oleh kerajaan Mahathir kerana dianggap menyerupai Barat dan bersifat kapitalis (Farish, 2016).

Dari sudut faktor dalaman pula, Wawasan 2020 yang digagaskan oleh Mahathir telah menjadi pendorong utama berlakunya penyebaran dasar Islamisasi di Malaysia. Memandangkan masyarakat perlu menghadapi cabaran untuk mencapai Wawasan 2020, maka Islam telah disesuaikan dengan matlamat untuk membangunkan negara agar tidak menjadi penghalang kemajuan kerana agama dan pembangunan perlu bergerak seiring. Menurut Mahathir "...there has never been a time when Muslims are looked so down upon, so treated with disrespect, as so oppressed as they are today. Will what we are doing today restore the greatness of our religion and the fikrah that it should be a mankind?...Frankly I don't think so. It is not because we are incapable of developing ourselves, but because we refuse to adhere to the true teachings of Islam. We ignore the Quranic injunction that Allah will not change our fate unless we strive to change it ourselves..." (Pandian 2005: 180). Di sebabkan dasar Islamisasi yang dijalankan lazim mendapat tafsiran negatif sebagai instrumen untuk melegitimasikan pemerintahan menerusi sokongan rakyat, maka UMNO 
berusaha untuk menangkis dakwaan-dakwaan sedemikian dengan meletakkan peranan Islam selari dengan keperluan pembangunan negara iaitu menerusi Wawasan 2020. Hal ini kerana, bagi UMNO, kemunduran masyarakat Islam adalah disebabkan oleh penolakan ilmu pengetahuan yang lain selain daripada agama Islam.

Menurut Pandian (2005), kerangka pemantapan dasar Islamisasi UMNO berlaku berasaskan kepada beberapa perkara. Pertama, pemantapan dasar Islamisasi berlaku disebabkan oleh tindak balas masyarakat yang menginginkan agar dasar Islamisasi diperkukuhkan. Pada peringkat awal, tindak balas masyarakat berpunca daripada pengaruh Revolusi Iran. Namun begitu, setelah pelbagai dasar Islamisasi dilakukan, masyarakat menuntut lebih banyak lagi dasar-dasar yang secara signifikannya memberi manfaat kepada masyarakat terutamanya orang Melayu. Kedua, pemantapan dasar Islamisasi berlaku sebagai strategi untuk berhadapan dengan PAS (Pandian 2005: 183). Memandangkan prinsip PAS pada ketika zaman Mahathir begitu terperosok dalam agenda konservatisme Islam, maka UMNO cuba membawa pendekatan bersifat moderat dengan memperkenalkan prinsip Islam modenis sebagai usaha untuk menarik elemen tradisional kepada perkembangan pembangunan negara khususnya bagi mencapai tujuan Wawasan 2020 (Hilley 2008: 13). Bagi UMNO, seandainya elemen-elemen tradisional keagamaan tidak dibawa selari dengan tema pembangunan negara, maka sudah pasti agenda kemajuan negara dan bangsa tidak dapat dicapai kerana masyarakat masih terikat dengan elemen konservatisme yang menjadi agen penetapan minda masyarakat untuk tidak bersifat terbuka dengan perubahan. Ketiga, pemantapan dasar Islamisasi dilakukan hasil daripada usaha pemimpin UMNO untuk membawa imej keislaman di dalam UMNO (Pandian 2005: 183). Aktor signifikan yang menggerakkan Islam di dalam UMNO adalah Anwar Ibrahim yang mana kemasukan Anwar ke dalam UMNO pada tahun 1982 telah berjaya menjadikan Islam sebagai dasar terpenting di dalam kerangka pentadbiran Malaysia.

Berdasarkan kepada justifikasi kerangka pemantapan dasar Islamisasi tersebut, maka UMNO telah menjalankan dasar Islamisasi menerusi beberapa strategi dan tindakan yang signifikan. Di antara strategi signifikan adalah menerusi hubungan Anwar dengan Angkatan Belia Islam Malaysia (ABIM) yang mana ia telah menjadi sandaran kepada kelangsungan dasar Islamisasi UMNO kerana secara praktikalnya, keanggotaan ABIM terdiri daripada golongan muda, profesional dan moderat yang banyak memberi sokongan kepada program-program Islamisasi UMNO. Selain itu, UMNO juga telah menubuhkan pelbagai institusi pembangunan yang bersifat keagamaan seperti penubuhan Universiti Islam Antarabangsa dan Bank Islam pada tahun 1983 serta beberapa lagi institusi hal ehwal keagamaan yang lain seperti Yayasan Dakwah, Pusat Islam dan Institut Kefahaman Islam Malaysia (IKIM) (Pandian 2005: 189). Disebalik kesemua dasar-dasar Islamisasi yang telah dijalankan, maka secara politiknya, UMNO berusaha untuk tidak membenarkan PAS menghakis hegemoni UMNO kerana PAS di bawah pimpinan Nik Aziz telah menggalang usaha mengukuhkan undang-undang Syariah khususnya di negeri Kelantan dan Terengganu (Hilley 2008: 13). Oleh sebab itu, UMNO menerusi pentabiran Mahathir begitu mempopularkan penerapan nilai-nilai Islam sehinggakan ia menjadi slogan kepada dasar Islamisasi UMNO. Pada masa yang sama, rasionalisasi UMNO dalam membawa proses Islamisasi di Malaysia adalah kerana untuk mempertahankan perpaduan negara memandangkan UMNO mendapat majoriti sokongan daripada mandat rakyat.I

PAS hanya mula bergerak ke aliran yang lebih sederhana selepas kemasukan golongan profesional secara besarbesaran ke dalam parti pada era Reformasi 1998. Golongan profesional yang turut dikenali sebagai golongan progresif ini kemudiannya merubah imej PAS kepada sebuah parti Islam yang moderat dan demokratik. Hal ini boleh dilihat apabila PAS mula memperkenalkan dasar Islamisasi yang lebih bertoleransi dengan kepelbagaian kaum dan agama di Malaysia.

\section{Metodologi}

Artikel ini menggunakan pendekatan kualitatif dengan reka bentuk kajian kes. Proses pengumpulan dan penjanaan data dilakukan dengan menggunakan sumber sekunder iaitu dokumen yang terdiri dari jurnal akademik dan buku ilmiah yang berkaitan dengan subjek kajian. Data kemudiannya di analisis dengan menggunakan metode interpretifdeskriptif. Melalui kaedah ini, penstrukturan semula data dilakukan secara berkronologi bagi mendapatkan gambaran yang lebih tepat tentang subjek kajian (Othman, 2015). Dapatan analisis kemudiannya turut disokong dengan sumber laporan dari portal berita yang diperoleh secara atas talian. Teori Islamisasi politik juga dipilih bagi memandu kajian untuk mencapai objektif yang ditetapkan.

\section{Kerangka Teoretikal Islamisasi Politik}

Sejarah Islamisasi politik bermula pada zaman Rasullulah S.A.W. apabila baginda memperkenalkan peraturan dan perlembagaan bertulis sebuah negara Islam pertama di dunia melalui Piagam Madinah pada tahun 622 Masihi. Piagam Madinah mengandungi 47 Fasal. 23 Fasal membincangkan tentang hubungan dan tanggungjawab dalam kalangan umat Islam manakala 24 fasal yang lain berkenaan tanggungjawab masyarakat bukan Islam termasuk kaum Yahudi terhadap negara Islam Madinah. Piagam Madinah menjadi asas terhadap usaha Islamisasi yang turut diguna pakai oleh pemimpin seterusnya sehingga membawa kepada kegemilangan tamadun Islam (Mazuki et al., 2013).

Hasil daripada pengenalan Islamisasi politik oleh Rasullulah S.A.W., maka dasar Islamisasi kemudiannya berkembang pada zaman pentadbiran Khulafa' Ar-Rasyidin yang menyebarkan Islam melalui penaklukan dan perluasan kuasa sehingga ke Rom, Parsi dan Syria. Melalui penaklukan, setiap tanah jajahan Islam diterapkan nilai- 
nilai pentadbiran Rasulullah S.A.W. berlandaskan Piagam Madinah, sekali gus memberikan impak kepada keberkesanan proses Islamisasi politik (Nasr, 2003). Proses Islamisasi kemudiannya berkembang kepada pentadbiran Bani Umayyah, pentadbiran Bani Abbasiyyah dan kerajaan Uthmaniyyah yang telah melakar kejayaan sebagai empayar Islam terunggul di dunia. Oleh itu, dapat dilihat bahawa proses Islamisasi yang bermula daripada Piagam Madinah kekal sebagai suatu landas kepada kejayaan perkembangan proses Islamisasi di serata dunia seperti India, China dan termasuklah Kepulauan Melayu. Di Malaysia, proses Islamisasi adalah sangat penting kerana ia mempengaruhi corak politik di Malaysia yang majoriti rakyatnya berbangsa Melayu dan beragama Islam (Noh, 2015).

Menurut Emile Nakhleh (2009), kesedaran kepada Islamisasi dalam konteks dunia moden mula dirasakan seawal tahun 1990-an apabila wujud perubahan yang semakin meningkat dalam kalangan masyarakat Muslim global terhadap iman dan keimanan yang menjadi panduan dalam aktiviti sosial dan politik masyarakat. Di samping itu, kelemahan dari segi politik, ekonomi dan ketenteraan umat Islam pada era moden yang berpunca dari kurangnya pegangan terhadap nilai-nilai Islam telah mendorong keperluan untuk mengembalikan sistem pemerintahan dan perundangan yang berteraskan Islam melalui Islamisasi (Nakhleh, 2009). Dapat disaksikan terdapat pelbagai parti politik Islam menyebarkan slogan dengan mengambil inti-pati Al-Quran dan Sunnah dalam menggerakkan motif politik seperti ketika pilihan raya dan dalam pentadbiran kerajaan. Justeru, pendekatan konsep Islamisasi melibatkan perbincangan terhadap nilai-nilai keagamaan dalam kehidupan masyarakat yang seterusnya mempengaruhi Islamisasi politik (Muzaffar, 1986).

Proses Islamisasi politik berlaku secara berbeza bagi setiap kumpulan dan negara. Menurut Emile Nakhleh (2009), terdapat dua tahap proses Islamisasi yang berlegar dalam kerangka pembangunan dasar Islamisasi sesebuah negara. Tahap pertama melibatkan entiti individu yang menyebarkan perjuangan Islam terhadap komuniti dengan memberi tumpuan untuk mempromosikan syariat Islam seperti solat, puasa, zakat dan haji sebagai landas Islamisasi setempat berskala kecil dan sederhana. Pada tahap ini, ia tidak melibatkan sebarang gerakan Islamisasi politik (Nakhleh, 2009). Tahap kedua merupakan tahap terpenting yang menggerakkan proses Islamisasi sehingga menjadi dasar bagi sesebuah negara. Rentetan dari peranan individu pada tahap pertama, pada tahap kedua ini wujud gerakan Islamisasi politik daripada para aktivis yang menekankan pengamalan nilai Islam dalam sistem bernegara berlandaskan Al-Quran dan Sunnah. Justeru, muncul aktor parti politik Islam yang membangkitkan isu berkaitan Islamisasi dan ideologinya sehingga mempengaruhi sistem politik khususnya pilihan raya dan pentadbiran kerajaan (Nakhleh, 2009). Walaubagaimanapun, wujud juga kecenderungan proses Islamisasi yang bersifat keganasan dan paksaan dalam menyebarkan nilai-nilai Islam atas beberapa faktor. Contohnya di Afrika Timur, kemunculan kumpulan radikal Islam berpunca dari kelemahan kerajaan dalam menguruskan ekonomi, kewujudan ideologi 'military based Islam', pengaruh kumpulan militan seperti Al-Qaeda dan tindak balas terhadap Islamofobia global (Rabasa, 2009).

Bagi mana-mana negara Islam, tahap kedua ini merupakan tahap paling kritikal kerana ia menentukan agenda dasar Islamisasi dapat mempengaruhi pembuatan keputusan kerajaan, sekali gus menarik sokongan masyarakat terhadap parti politik Islam.

\section{Hasil dan Perbincangan}

Terdapat empat dasar Islamisasi politik yang dilaksanakan oleh UMNO di bawah pentadbiran Abdullah Badawi dan Najib Razak iaitu Islam Hadhari, prinsip Wasatiyyah, Indeks Syariah Islam dan hubungan kerjasama UMNO dan PAS. Dasar Islamisasi kontemporari PAS pula terbahagi kepada dua fasa. Kedua-dua fasa ini dibezakan dengan pendekatan yang diperkenalkan oleh PAS sepanjang kepimpinan Abdul Hadi Awang (2002 hingga kini) sebagai presiden parti. Dasar berkenaan adalah agenda negara Islam, perlaksanaan hudud, Islamisasi demokrasi dan Negara Berkebajikan.

\section{Islam Hadhari}

Islam Hadhari diperkenalkan bagi memudahkan rakyat Malaysia khususnya yang beragama Islam untuk memahami makna Islam sebenar dan sekali gus mempraktikkan Islam secara menyeluruh sehingga dapat menghasilkan kemajuan beracuankan prinsip dan ajaran Islam yang mencakupi tuntutan dunia, akhirat, jasmani dan rohani. Sepuluh prinsip Islam Hadhari ialah keimanan dan ketaqwaan kepada Allah, kerajaan adil dan beramanah, rakyat berjiwa merdeka, penguasaan ilmu pengetahuan, pembangunan ekonomi seimbang dan komprehensif, kehidupan berkualiti, keutuhan budaya dan moral, pemeliharaan alam semula jadi, pembelaan hak kumpulan minoriti dan wanita serta kekuatan pertahanan (Razak \& Zakariah, 2010). Pengenalan Islam Hadhari telah menggariskan tujuan yang bersifat politik dan keselamatan. Dari sudut politik, Islam Hadhari berusaha untuk meraikan peranan Islam dalam mengurus tadbir negara dengan menjadikan ia sebagai suatu bentuk pembudayaan politik yang baharu. Dari sudut historis, pemimpin Malaysia terdahulu seperti Tunku Abdul Rahman, Tun Razak Hussein dan Tun Hussein Onn tidak berpeluang secara luas untuk menjadikan Islam sebagai kerangka signifikan dalam pembuatan dasar ekoran status negara baharu yang dimiliki oleh Malaysia.

Selain itu, Islam Hadhari bertujuan untuk memisahkan Islam daripada fahaman Mahathirisme yang menjadi instrumen persaingan politik dengan PAS. Oleh itu, Islam Hadhari secara dasarnya dilihat sebagai lengkap, sederhana dan inklusif serta turut terbuka pengaplikasiannya kepada orang bukan Islam (Salleh, 2005). Dari sudut tujuan 
keselamatan, Islam Hadhari berusaha untuk mengekang ekstrimisme keganasan dan politik. Memandangkan peristiwa keganasan pada 11 September 2001 yang berlaku di Amerika Syarikat telah mencetuskan situasi Islamophobia, maka Islam Hadhari bertindak sebagai alternatif dalam mengatasi isu ekstrimisme dan keganasan global. Tujuan ini dilihat selari dengan pandangan daripada mantan Menteri Luar Malaysia iaitu Syed Hamid Albar yang menyatakan bahawa "...Islam Hadhari will enable Islamic and non-Islamic countries to communicate better. It is important to correct the image of Muslims, who are now being linked to murder and acts of terror..." (Ali, 2016). Selain itu, Islam Hadhari berusaha untuk mengurangkan polemik politik ekstrimis Islam yang diamalkan oleh PAS memandangkan timbulnya pelbagai isu keagamaan seperti isu kafir-mengkafir, sembahyang dua imam dan memulaukan kenduri yang dibuat oleh penyokong UMNO. Justeru, pendekatan Islam Hadhari adalah satu pendekatan halus kerajaan bagi memenangi hati dan pemikiran golongan ekstrimis agar kembali kepada golongan majoriti dalam persekitaran politik Malaysia (Shuib, 2007).

Penekanan yang mendalam terhadap Islam Hadhari telah menjadikan isu Islam sebagai kritikan utama ketika pentadbiran Abdullah. Sifat berlebihan dan eksklusif telah diterjemahkan ke dalam beberapa isu. Pertama adalah berkenaan dengan isu Perkara 11 Perlembagaan Persekutuan yang memperuntukkan mengenai kebebasan beragama di dalam Persekutuan (Perlembagaan Persekutuan 2010). Ironinya, kesamarataan dan kebebasan beragama telah pun dinafikan dalam pentadbiran Abdullah apabila Abdullah menolak sebarang perbincangan antara agama kerana khuatir akan berlakunya ketegangan kaum. Disebalik retorik Abdullah untuk mengharmonikan isu agama yang selama ini kurang diberi perhatian oleh pemimpin terdahulu, Abdullah sebenarnya telah menolak usaha untuk menyatukan agama apabila beliau menolak usul daripada NGO Artikel 11 agar kerajaan menubuhkan Suruhanjaya Antara Agama bagi meraikan peranan agama secara baik (Welsh \& Chin, 2014).

Pada masa yang sama, diskriminasi keagamaan ke atas bukan Islam turut berlaku pada takat yang tinggi. Misalannya seperti penyukaran kelulusan proses pembinaan kuil dan gereja, ketiadaan badan rasmi yang menguruskan hal ehwal bukan Islam, penerapan nilai Islam menjadi dasar rasmi pentadbiran, pemusnahan sebanyak 50 kuil-kuil Hindu seperti di Kampung Rimba Jaya dan Padang Jawa, Shah Alam, isu tembakan suspek India oleh pihak polis dan isu pertukaran agama Islam-Hindu yang dikatakan lebih memihak kepada agama Islam (Kabilan, 2013). Justeru, konsep Islam Hadhari yang bersifat inklusif, secara praktikalnya gagal kerana pergeseran politik melibatkan agama menjadi semakin luas. Malah, dasar Islamisasi Abdullah gagal mengawal lebihan isu birokrasi agama sedangkan prinsip Islam Hadhari menggariskan perlindungan hak minoriti.

\section{Prinsip Wasatiyyah}

Prinsip wasatiyyah telah diperkenalkan oleh Najib Razak sebagai suatu pegangan untuk tidak bersikap berlebihlebihan dalam mengurus tadbir negara yang mana prinsip wasatiyyah telah mendasari Gagasan 1Malaysia yang menekankan tema "Rakyat Didahulukan, Pencapaian Diutamakan". Dari sudut bahasa, wasatiyyah bermaksud sederhana, pertengahan, berimbang (al-tawazun) dan adil (al-adlu) (Majlis Dakwah Agama, 2015). Pendekatan wasatiyyah digunakan dalam konteks pengurusan negara untuk membezakan pendekatan "ifrat" iaitu pendekatan yang rigid dan ekstrem (pengetat agama) serta pendekatan "tafrit" iaitu pendekatan yang longgar dan terlalu liberal (pelonggar agama) (Majlis Dakwah Negara, 2015). Walaupun UMNO melihat signifikan prinsip wasatiyyah dalam konteks ingin menjadikan Malaysia sebagai sebuah negara Islam moden dan progresif, namun terdapat kritikan yang melihat prinsip wasatiyyah sebagai agenda baharu menggantikan gagasan 1Malaysia. Kritikan terhadap prinsip wasatiyyah UMNO telah dibangkitkan oleh Tuan Ibrahim Tuan Man melihat kemunculan prinsip Wasatiyyah adalah alternatif untuk menggantikan konsep 1Malaysia yang dianggap gagal, sekali gus ingin meraih undi masyarakat ketika PRU-13 (Dewan Pemuda PAS 2011).

Pada masa yang sama, disebalik tujuan kepada pegangan prinsip wasatiyyah untuk mengekang ekstrimisme, telah wujud keraguan mengenai aplikasi UMNO terhadap prinsip wasatiyyah. Kritikan ini telah disuarakan oleh Lim Kit Siang dengan menyatakan bahawa kerajaan tidak benar-benar mempraktikkan prinsip wasatiyyah dalam urus tadbir kerana pelanggaran terhadap nilai kebebasan, akauntabiliti dan keadilan masih lagi berlaku pada takat yang tinggi (Lim, 2016). Laungan prinsip wasatiyyah dalam pentadbiran Najib dilihat sebagai retorik kerana dengan adanya pengukuhan undang-undang bersifat drakonian di Malaysia, adalah mustahil untuk mewujudkan keadilan, kesederhanaan dan keseimbangan dalam urus tadbir negara seperti mana yang ditekankan dalam prinsip wasatiyyah. Justeru, dasar Islamisasi UMNO melalui agenda wasatiyyah sukar dinilai keberkesanannya memandangkan terdapat kritikan dan kelemahan yang perlu diperbaiki.

\section{Indeks Syariah Malaysia}

Pengenalan Indeks Syariah Malaysia (ISM) telah dicetuskan oleh Najib pada tahun 2014 sebagai pelengkap tadbir urus Islam di Malaysia yang boleh dianggap mempunyai nilai-nilai perintis kerana ia adalah menyeluruh, komprehensif dan yang pertama seumpamanya di dunia. Signifikannya ISM adalah kerana ia disandari dengan Maqasid Syariah sebagai landasan kerajaan dalam menepati piawaian Islam berkaitan dasar dan program kerajaan yang dilaksanakan dari tahun ke tahun. Dari sudut bahasa, "syariah" merujuk kepada perintah Allah yang disampaikan melalui Al-Quran dan As-Sunnah. Manakala "Maqasid Syariah" merupakan objektif utama syariah dalam memelihara agama, nyawa, 
akal, keturunan dan harta untuk kebajikan manusia (JAKIM, 2015). Secara asasnya, ISM berperanan untuk mengukur lapan bidang utama iaitu perundangan Islam, politik, ekonomi, pendidikan, kesihatan, budaya, prasarana dan persekitaran serta sosial agar selari dengan keperluan Maqasid Syariah (JAKIM, 2015). Meskipun wujud andaian bahawa UMNO tidak pernah bersungguh-sungguh untuk memartabatkan Islam meskipun dasar Islamisasi telah digiat dijalankan sejak tahun 1981 lagi, namun Najib berusaha menafikan andaian berkenaan. Menurut Najib, ISM menjadi penanda aras usaha UMNO untuk memartabatkan syiar dan syariat Islam (BH Online, 2015). Pada masa yang sama, pandangan daripada Shamsul Iskandar Mohd Akin turut bersetuju dengan pengenalan ISM ekoran wujudnya pelbagai polemik di dalam negara. ISM dilihat sebagai langkah pemula kerajaan dalam mengimarahkan prinsip dan sistem nilai Islam dalam tadbir urus kerajaan memandangkan terdapat pelbagai isu khususnya ketirisan kewangan yang melibatkan kerajaan (Akim, 2015).

Melihat kepada kesungguhan UMNO untuk mengurus tadbir negara mengikut prinsip Maqasid Syariah, maka pada tahun 2015, Malaysia memperoleh skor keseluruhan Indeks Syariah Malaysia sebanyak 75.4\% (Malaymail Online, 2016). Walhal bagaimanapun, terdapat kritikan yang mempersoalkan skor ISM. Menurut Mujahid Yusof Rawa,“...apa yang menjadi persoalan, bagaimana kayu pengukur dibuat dalam aspek maqasid (objektif syariah) dalam hal menjaga dan memelihara harta dan kewangan sedangkan berbagai salah laku tata kelola kewangan telah membawa kesan buruk kepada negara? Ini tidak termasuk kes 1MDB, RM 2.6 bilion, ketirisan dan lain-lain salah guna kuasa. Apakah ini patuh syariah? Indeks syariah yang diperoleh secara dalaman oleh jawatankuasa ini perlu dibuat pengesahan di peringkat luar yang bebas agar piawaian syariah dapat kekal pada aras yang tinggi dan tidak dipermudah-mudahkan..." (Rawa, 2016). Walaupun terdapat kritikan terhadap ISM, tetapi ia sebenarnya telah membawa Malaysia ke suatu tahap perkembangan Islamisasi di luar kebiasaan berbanding dasar-dasar Islamisasi sebelum ini. Bahkan, tidak dinafikan bahawa ISM merupakan agenda Islamisasi popular yang mendapat perhatian masyarakat pada ketika ini. Hal ini kerana, wujud pengharapan daripada masyarakat agar ISM menjadi titik tolak kepada pembasmian isu-isu urus tadbir seperti rasuah, ketidak-samarataan dan keadilan.

\section{Hubungan Kerjasama UMNO-PAS}

Hubungan yang baik di antara UMNO dan PAS semenjak penghujung tahun 2015 memperlihatkan UMNO mula menjalankan dasar Islamisasi secara diplomasi dengan PAS sebagai cubaan tahaluf siyasi (kerjasama politik). Kecenderungan untuk menjalinkan kerjasama politik pada peringkat awal telah disampaikan oleh Najib ketika Perhimpunan Agung UMNO 2015 apabila Najib menjemput PAS menjalinkan kerjasama demi kepentingan Melayu/Bumiputera dan Islam (Astro Awani, 2015). Pelawaan Najib untuk menjalinkan kerjasama politik telah mendapat perhatian PAS apabila kedua-dua pemimpin tersebut telah menghadiri Multaqa Serantau Alumni Al-Azhar Malaysia 2015 (Malaysiakini, 2015). Kemudian pada Disember 2016, UMNO dan PAS bersama-sama berganding bahu berhimpun di dalam Himpunan Solidariti untuk Rohingya 2016 yang mana perhimpunan tersebut dihadiri oleh pemimpin-pemimpin besar UMNO dan PAS seperti Najib Razak, Zahid Hamidi, Hadi Awang, Tuan Ibrahim, Nik Abduh dan Takiyuddin Hassan (Muhammad, 2016). Oleh itu, hubungan baik yang ditonjolkan oleh UMNO-PAS telah menjadi perintis kemungkinan berlakunya kerjasama perpaduan di antara UMNO dan PAS.

Selain daripada hubungan mesra yang ditonjolkan di antara UMNO dan PAS, UMNO dilihat cuba untuk menterjemahkan sebaik mungkin dasar Islamisasi menerusi sokongan untuk membenarkan PAS membentang Rang Undang-Undang (RUU) 355 di Parlimen. Secara tradisinya, sepanjang 20 tahun yang lepas, UMNO tidak pernah memberikan sebarang kerjasama untuk membenarkan PAS menjalankan undang-undang Syariah melebihi peruntukan 3-5-6 sedia ada. Peruntukan 3-5-6 merujuk kepada hukuman 3 tahun penjara, denda sebanyak RM5,000 dan sebatan sebanyak 6 kali (Chin, 2016). Tentangan untuk menggubal RUU 355 boleh dilihat menerusi dua faktor. Dari sudut politik, pakatan BN hanya terdiri daripada satu sahaja parti Muslim majoriti iaitu UMNO. Justeru, sekiranya UMNO membenarkan RUU 355 digubal, UMNO dilihat tidak berlaku adil kepada parti-parti komponen BN yang lain. Dari sudut perundangan pula, situasi kacau bilau perundangan akan berlaku kerana wujud ketidaksamarataan undangundang terhadap pelaksanaan hukuman akibat polarisasi Mahkamah Syariah dan Mahkamah Sivil (Chin, 2016). Secara analoginya, adalah sesuatu yang tidak adil sekiranya orang Islam dihukum memotong tangan kerana mencuri sedangkan orang bukan Islam pula dikenakan hukuman penjara ataupun denda dengan tahap kesalahan yang sama. Justeru, penggubalan RUU 355 untuk menghapuskan peruntukan 3-5-6 dilihat sebagai tidak adil kepada masyarakat. Pada Mei 2016, kerajaan buat pertama kali membenarkan PAS membentangkan RUU 355 di Parlimen. Di pihak UMNO, sokongan ke atas RUU 355 dibuat atas dasar syariah yang mana RUU 355 tidak sama sekali menyentuh kepentingan dan kedudukan semua golongan (UMNO Online 2016). Tetapi, secara harfiahnya, justifikasi UMNO membenarkan PAS membentangkan RUU 355 adalah untuk meraih sokongan daripada kelompok konservatif Islam sekali gus berharapan agar suatu bentuk kerjasama dapat dijalinkan bersama PAS.

\section{Agenda Negara Islam}

Agenda negara Islam telah menjadi sebahagian dari perjuangan PAS sejak era kepimpinan Abbas Alias (1953 hingga 1956) sebagai presiden lagi (Ismail 2011). Bagaimanapun, impian PAS ini hanya mulai kukuh bermula era kepimpinan ulama pada tahun 1983 selepas didorong oleh faktor kejayaan Iran dalam membentuk pemerintahan 
republik Islam dibawah pimpinan ulama. Definisi sebenar PAS mengenai misinya untuk mendirikan sebuah negara Islam boleh diteliti melalui 'Dokumen Negara Islam' yang dikeluarkan PAS melalui Abdul Hadi dan Haron Din pada tahun 2003. Melalui dokumen ini, PAS menjelaskan secara terperinci prinsip dan kaedah perlaksanaan bagi mewujudkan negara Islam di Malaysia. Menurut Mohd Syakir Roshdi (2011), definisi negara Islam seperti mana yang tertulis di dalam Dokumen Negara Islam 2003 dimaksudkan sebagai sebuah negara kebajikan yang dipimpin oleh kepimpinan yang bertaqwa, yang diasaskan atas prinsip syarak dengan melaksanakan segala syariat dan hukum Allah, demi mendaulatkan Islam sebagai ad-deen (pegangan atau cara hidup) yang lengkap dan sempurna menuju kebahagiaan di dunia dan akhirat. Perjuangan menegakkan sebuah negara Islam di Malaysia menurut PAS adalah atas kefahaman bahawa Islam adalah cara hidup yang menyeluruh termasuklah agama dan kerajaan yang sama sekali tidak terpisah antara keduanya.

Asas pendirian sebuah negara Islam yang dinyatakan dalam dokumen berkenaan bagaimanapun berdepan kritikan. Dokumen tersebut dianggap sebagai tidak memberikan penjelasan yang lengkap, teliti, dan terperinci, selain mempunyai kelemahan yang begitu banyak (Aziz, 2003). Dokumen ini juga dianggap sebagai tidak realistik dan tidak relevan untuk dilaksanakan. Selain hanya mengulangi tujuh perkara yang terkandung dalam memorandum negara Islam PAS yang juga pernah dibentangkan oleh Fadzil Noor, keseluruhan isi kandungan dokumen yang tidak terperinci tersebut juga dianggap sebagai telah pun dilaksanakan oleh kerajaan UMNO (Aziz, 2003). DAP sebagai sebuah parti yang bermatlamat menjadikan Malaysia sebagai sebuah negara sekular juga mengambil pendekatan menolak Dokumen Negara Islam yang dilancarkan oleh PAS. Menurut Lim Kit Siang, dokumen tersebut dianggap sebagai sebuah dokumen yang tidak demokratik dan bertentangan dengan hak asasi rakyat bukan Islam serta semangat kontrak sosial yang telah dibentuk oleh pemimpin pelbagai kaum sebelum kemerdekaan negara lagi. Selain itu, DAP juga beranggapan agenda negara Islam PAS dengan merujuk dokumen tersebut juga adalah mustahil untuk dilaksanakan di Malaysia. Hal ini kerana idea negara teokrasi yang diperjuangkan oleh PAS tersebut dalam masa yang sama juga bertentangan dengan Perlembagaan Persekutuan, Perjanjian Malaysia 1963, Rukun negara 1970, serta Manifesto Bersama Pembangkang yang dicapai pada tahun 1999 (Ibrahim, 2013).

\section{Perlaksanaan Hudud}

Polemik pelaksanaan hukum hudud di Malaysia oleh PAS bermula sekitar tahun 1990-an selepas PAS menawan semula negeri Kelantan pada PRU 1990, yang juga merupakan kejayaan besar pertama selepas golongan ulama mendominasi parti berkenaan. Hudud berasal dari perkataan bahasa Arab yang bererti sekatan, penghalang, atau batasan. Dari maksud tersebut, hudud merupakan hukuman yang dapat mencegah dan menjadi pengajaran kepada pesalah daripada terus melakukannya. Hudud merupakan salah satu daripada tiga bentuk kesalahan atau hukuman yang terdapat dalam Hukum Jenayah Syariah. Terdapat enam hingga tujuh jenis kesalahan dan jenayah yang termasuk di bawah hukuman ini iaitu; mencuri, merompak, zina, menuduh zina, kesalahan minum arak, murtad, dan bughah atau pemberontak yang kesemuanya dinyatakan secara jelas di dalam al-Quran. Matlamat untuk mengimplementasi hukum hudud ini selari dengan matlamat PAS bagi menjadikan Malaysia sebagai sebuah negara Islam. Bagaimanapun, PAS berhadapan dengan satu lagi rintangan besar sebelum hudud benar-benar boleh dilaksanakan. Hudud hanya boleh dilaksanakan PAS (di peringkat negeri pemerintahannya) setelah pindaan terhadap Akta Mahkamah Syariah dalam Perlembagaan Persekutuan dilakukan dan diluluskan oleh Parlimen (Saat, 2015).

Pada tahun 1993, Dewan Undangan negeri (DUN) Kelantan meluluskan Rang Undang-Undang (RUU) Kod Jenayah Syariah Kelantan begi membolehkan hudud dilaksanakan di negeri berkenaan. Antara yang terkandung dalam RUU tersebut adalah berkenaan dengan hukuman terhadap jenayah mencuri, zina, liwat, murtad, serta peruntukan berkenaan qisas dan diyat (Noor, 2016). Bagaimanapun, RUU ini akhirnya ditolak oleh kerajaan Persekutuan kerana dianggap bertentangan dengan Perlembagaan. Bagaimanapun, usaha PAS untuk melaksanakan hudud ini diteruskan pada tahun 2002 di negeri Terengganu setelah PAS menawan negeri berkenaan pada PRU 1999 dan sekali lagi menemui kegagalan berikutan penolakan Kerajaan Persekutuan terhadap RUU berkenaan. Impian PAS kemudiannya dipertegaskan lagi melalui Dokumen Negara Islam PAS yang dikeluarkan pada tahun 2003 yang menyebutkan pelaksanaan hudud adalah wajib kerana merupakan perintah Allah S.W.T. Sepanjang tahun 2005 hingga 2015, agenda perlaksanaan hudud dilihat pudar terutama selepas PAS mengadakan kerjasama politik dalam Pakatan Rakyat.

PAS bagaimanapun sekali lagi mengejutkan politik Malaysia, terutama kepada rakan-rakan pakatan pembangkangnya pada tahun 2014 apabila mengusulkan pindaan Enakmen Kanun Jenayah Syariah II (1993) bagi membolehkan hudud diimplementasikan di Kelantan. Usul ini kemudiannya dibentang pada tahun 2015 dan disokong serta diluluskan oleh ahli DUN negeri Kelantan termasuk wakil BN dengan sekali lagi menegaskan bahawa hukum hudud yang ingin dilaksanakan PAS hanya terguna pakai bagi penganut agama Islam sahaja dan tidak langsung melibatkan penganut agama lain (Zain, 2015). Pada 26 Mei 2016, buat pertama kalinya dalam sejarah pihak kerajaan membenarkan usul RUU Persendirian Akta 355 dibentangkan di Parlimen oleh Abdul Hadi Awang. Pindaan Akta Mahkamah Syariah (Bidang Kuasa Jenayah) 1965 ini akan membuka laluan pelaksaan hudud di Kelantan dengan memansuhkan keterbatasan hukuman yang boleh dilaksanakan oleh Mahkamah Syariah (Zulkifli, 2016). Usul ini kemudiannya menerima cabaran hebat apabila hampir keseluruhan parti bukan Islam dari kerajaan dan pembangkang menentang usaha UMNO dan PAS berkenaan (Grewal, 2016). 


\section{Islamisasi Demokrasi}

Wacana mengenai kedudukan dan amalan demokrasi dalam PAS berpecah kepada dua pandangan. Tanggapan pertama adalah bahawa demokrasi hanyalah "kenderaan" yang digunakan oleh PAS bagi mencapai matlamat. Setelah mencapai kemenangan politik, PAS kemudiannya akan melaksanakan matlamat dan tujuannya (negara Islam dan hudud). Pandangan kedua pula cenderung untuk menyokong demokrasi sebagai asas perjuangan politikal Islam. Pandangan ini melihat demokrasi dan pendemokrasian dalam jangka masa panjang dan komited melaksanakannya bagi mencapai tujuan dan matlamat PAS (Harakah Daily, 2015).

Perjuangan PAS terhadap pendemokrasian bermula pada era Reformasi pada 1998 di bawah kepimpinan presiden Fadzil Noor (1989 hingga 2002). Tahun 1998 menyaksikan perubahan landskap politik di Malaysia yang semakin menjadi lebih terbuka, dan dipengaruhi oleh wacana politik berkenaan demokrasi, keadilan, kebebasan, dan tadbir urus yang baik. Perubahan ini dalam masa yang sama turut menenggelamkan perjuangan Islamisme negara Islam yang diperjuangkan oleh PAS sebelumnya. Maka, PAS juga mula membuat keputusan untuk mengubah pendekatan parti menjadi lebih bersifat toleransi bagi menyesuaikan dengan realiti politik yang berlaku ketika itu (Zain, 2014). Ketika era ini, PAS antara parti oposisi yang lantang dalam memperjuangkan nilai-nilai demokrasi terutama yang berkaitan dengan hak asasi manusia. Antara usaha yang dilakukan adalah dengan menekan kerajaan UMNO bagi memansuhkan ISA. Fadzil juga merupakan Presiden PAS pertama yang mengadakan pakatan politik dengan parti sekular DAP yang terkenal dengan kelantangannya menentang negara Islam dan hudud. Bagaimanapun perjuangan demokrasi PAS terhenti selepas berlakunya pertukaran pucuk kepimpinan pada tahun 2002 yang menyaksikan parti itu kembali pada pendekatan konservatif semula.

Mulai tahun 2005, PAS melalui usaha golongan prodemokrat dalam parti mula mempromosikan imej PAS sebagai sebuah parti Islam yang memperjuangkan demokrasi dan hak asasi manusia. Hal ini didorong dengan kuat oleh faktor luaran di mana golongan profesional dalam parti mula mengadakan hubungan baik dengan parti Islamis moderat dari negara luar seperti AKP dan En-Nahda. Model parti ini kemudiannya digunakan oleh mereka bagi diimplementasikan kepada suasana sosiopolitik di Malaysia. Tahalluf siyasi yang diadakan PAS bersama PKR dan DAP dalam PR pada tahun 2008 merupakan salah satu kejayaan kumpulan prodemokrat dalam memperjuangkan demokrasi. Dengan matlamat bagi menjatuhkan pemerintah UMNO-BN, PAS akhirnya bersedia menggugurkan perjuangan negara Islamnya. PR lebih mengutamakan hal-hal yang boleh disepakati secara konsensus seperti isu mengenai demokrasi, keadilan, kebebasan, dan pemerintahan yang baik (Zain, 2014). Pakatan atas nama perjuangan demokrasi ini ternyata berjaya pada PRU 2008 apabila prestasi PAS meningkat dengan sangat ketara selain dapat menghapuskan tradisi penguasaan dua per tiga BN di Parlimen.

\section{Negara Berkebajikan}

Negara berkebajikan mula diperkenalkan oleh PAS menjelang PRU 2008. Pada November 2006, Dzulkefly Ahmad dan Hatta Ramli telah mewakili PAS ke persidangan Dialogue with the Muslim World di Berlin, Jerman. Dialog ini memberi peluang kepada gerakan Islam berkongsikan pengalaman mereka terhadap proses politik kepada pembuat polisi, pelajar, diplomat, dan pemimpin parti di Jerman. Ketika inilah PAS mengadakan pertemuan dengan pemimpin Parti Sosial Demokrat Jerman dan membincangkan tentang konsep welfare state di negara itu. Perbincangan inilah yang kemudiannya memberikan idea kepada PAS untuk tampil dengan idea negara berkebajikan bagi menggantikan negara Islam (Farish, 2016).

Negara Berkebajikan (Islamic Walfare State) diperkenalkan sebagai satu alternatif model tadbir urus kerajaan yang menepati citra Islam. Presiden Abdul Hadi mendefinisikan negara berkebajikan Islam yang ingin dibawa oleh PAS sebagai sebuah negara yang akan memberikan keutamaan kepada kebajikan dan keselesaan rakyat sebagai agenda utama pembangunan negara. walaupun penumpuan negara ini adalah terhadap pembangunan, tetapi matlamat yang lebih utama untuk dicapai adalah kesejahteraan rakyat (Roshdi, 2011). Negara berkebajikan ini juga bermaksud “...rakyat dan kerajaan sentiasa berlumba-lumba untuk melakukan kebajikan. Sistem sokongan yang cekap dan menguntungkan kesemua rakyat juga akan dibina..." (Awang, 2011). Negara berkebajikan yang diperkenalkan oleh PAS ini juga dilihat jauh lebih terbuka dan bersifat inklusif berbanding negara Islam yang dilihat hanya eksklusif untuk orang Islam sahaja.

PAS juga telah menerbitkan dua dokumen yang berkaitan dengan negara berkebajikan iaitu; Konsep Asas Negara Kebajikan serta Negara Berkebajikan: Tawaran PAS. Menurut PAS, konsep negara berkebajikan ini tidak lari dari panduan bernegara yang ditetapkan oleh al-Quran. Ironinya, negara berkebajikan yang diperkenalkan juga tidak langsung menyentuh isu hudud. Sepuluh agenda utama digariskan secara terperinci melalui gagasan negara berkebajikan yang antaranya adalah mengenai; kerajaan yang amanah, adil, dan bersih, masyarakat penyayang, aman, dan bersatu, serta ekonomi yang mampan, seimbang, dan saksama (Lee, 2011). Selain itu, negara berkebajikan ini juga akan menjadi prinsip penggubalan tiga polisi utama iaitu politik, ekonomi, dan sosial sekiranya PAS diberikan berjaya memerintah (Yatim, 2011). Jelasnya melalui agenda ini, PAS telah berjaya muncul sebagai sebuah parti yang lebih sederhana, relevan dengan masyarakat majmuk Malaysia, dan tidak lagi bersandar kepada retorik politik. 


\section{Kesimpulan}

Sebagai kesimpulannya, Islamisasi politik pada era kontemporari di Malaysia ditunjangi oleh dua parti politik dominan Melayu-Islam iaitu UMNO dan PAS. Kedua-duanya saling bersaing dalam melaksanakan dasar Islamisasi terhadap masyarakat melalui pendekatan politik masing-masing. Bermula 1980-an, Islam menjadi satu agenda utama dalam politik tanah air dan berlangsung sehingga kini. Dasar Islamisasi yang dijalankan semenjak dari zaman Rasulullah S.A.W. hingga ke zaman Turki Uthmaniyyah telah menjadi contoh terbaik bagi UMNO dan PAS untuk memperjuangkan dasar-dasar Islamisasi bagi mengenengahkan idea Islam dalam pemerintahan. Penerapan nilai-nilai Islam menerusi dasar-dasar Islamisasi yang diterapkan sejak zaman pentadbiran Mahathir sehingga ke zaman Najib Razak dan Abdul Hadi Awang telah memberi fahaman bahawa Islam masih menjadi indikasi utama dalam mengurus tadbir negara. Dasar Islamisasi UMNO secara tidak langsung telah membawa suatu bentuk tahalluf siyasi dengan PAS pada hari ini. Walaupun Islam bukanlah faktor dominan kepada kerjasama hubungan UMNO-PAS, tetapi ia sekurangkurangnya telah memberi harapan besar kepada landskap politik Malaysia.

\section{Penghargaan}

Penulis ingin mengucapkan terima kasih kepada Universiti Tun Hussein Onn Malaysia, Batu Pahat, Malaysia atas bantuan dan maklumat yang diberikan untuk memastikan kejayaan kajian ini.

\section{Rujukan}

[1] Akim, S. I. M. (2015). Teladani Nabi: Wasatiyyah bukan sekadar retorik. Malaysiakini. 4 Januari. http://www.malaysiakini.com/letters/285292

[2] Ali, M. (2016). Malaysia's Islam Hadhari and the role of nation state in international relations. In Abdelkader, D., Adiong, N. M. \& Mauriello, R. (Ed.). Islam and International Relations: Contributions to Theories and Practice. Hampshire: Palgrave Macmillan

[3] Angel Rabasa (2009). Radical Islam in East Africa. Santa Monica: RAND Corporation

[4] Armstrong, K. (2002). Islam A Short History. United States: Modern Library

[5] Astro Awani (2015). Ucapan Presiden pada Perhimpunan Agung UMNO 2015 (teks penuh). 10 Disember. http://www.astroawani.com/berita-politik/ucapan-presiden-pada-perhimpunan-agung-umno-2015-teks-penuh84648

[6] Awang, A. H. (2011). Konsep Asas Negara Berkebajikan. Kuala Lumpur: Lajnah Penerbitan Dewan Ulama PAS Pusat

[7] Aziz, A. (2003). Dokumen Negara Islam gagal beri penjelasan bermakna. Malaysiakini. 12 November. https://www.malaysiakini.com/letters/26510

[8] Badlihisham Mohd Nasir \& Napisah Karimah Ismail (2011). Kepimpinan dan Kedudukan Ulama dalam Organisasi Parti Islam Se-Malaysia (PAS). Prosiding Nadwah Ulama Nusantara (NUN) IV: Ulama Pemacu Transformasi Negara, hlm. 116-123

[9] BH Online (2014). Najib: Indeks Syariah Malaysia bukti UMNO martabatkan Islam. 30 Januari. http://www.bharian.com.my/node/32436

[10] Chin, J. (2016). Malaysia: heading for syariah domination? The Round Table 105(6): 737-739

[11] Dewan Pemuda PAS. 2011. Wasatiyyah gagasan baru Umno lawan 1Malaysia? 28 November. http://dewanpemudapaskawasanmachang.blogspot.my/2011/11/wasatiyyah-gagasan-baru-umno-lawan.html

[12] Farish A. Noor (2016). The Malaysian Islamic Party PAS 1951-2013: Islamism in a Mottled Nation. Ulang Cetak. Petaling Jaya: Strategic Information and Research Development Centre

[13] Grewal, I. S. (2016). MB Kelantan selesai bentang pindaan enakmen hudud, ADUN UMNO sokong. Astro Awani. 18 Mac 2015. http://www.astroawani.com/berita-politik/mb-kelantan-selesai-bentang-pindaan-enakmenhudud-adun-umno-sokong-55895

[14] Gurbuz, M. V. (2003). The Iranian revolution. Faculty of Political Science Journal 25(4): 107-122

[15] Hilley, J. (2008). Malaysia: Mahathirisme, Hegemoni dan Pembangkang Baru (Trans.). Kuala Lumpur: Institut Terjemahan Negara Malaysia Berhad

[16] Ibrahim, M. (2013). PAS tersepit kerana ugutan DAP. Sinar Online. 26 April. http://www.sinarharian.com.my/kolumnis/pas-tersepit-kerana-ugutan-dap-1.154204

[17] Ismail, D. (2016). Laporan Indeks Syariah Malaysia tidak perlu dipertikai. Malaysia Dateline. 18 April. http://malaysiadateline.com/index.php/berita-list/15-berita/2222-laporan-indeks-syariah-malaysia-tidak-perludipertikai

[18] Jaafar, K. (1980). Dr. Burhanuddin Al-Helmy: Islam dan Kebangsaan Melayu. Kuala Lumpur: Penerbitan Yayasan Anda

[19] JAKIM (2015). Indeks Syariah Malaysia: Model Tadbir Urus Berteraskan Maqasid Syariah. Putrajaya: Jabatan Kemajuan Islam Malaysia 
[20] Kabilan, K. (2013). The Indian dilemma: sucked up \& spat out. In Welsh, B. \& Chin, J.U.H. (Ed.). Awakening: the Abdullah Badawi Years in Malaysia. Petaling Jaya: Strategic Information Research Development (SIRD)

[21] Lee, L. H. (2011). Negara Berkebajikan PAS kini tanpa hukum hudud. Malaysiakini. 11 Disember. https://www.malaysiakini.com/news/183851

[22] Lim, K. S. (2016). Fikrah ekstrem mufti: mana wasatiyyah Najib Razak? Roketkini.com. 29 Jun. http://www.roketkini.com/2016/06/29/fikrah-ekstrem-mufti-mana-wasatiyyah-najib-razak/

[23] Majlis Dakwah Negara. 2015. Definisi wasatiyyah dan penghayatan wasatiyyah. 10 April. http://www.mdn.org.my/?p=967

[24] Malaymail Online (2016). . Indeks Syariah: Malaysia beri markah 75.42 peratus kepada diri sendiri. 28 Mac. http://www.themalaymailonline.com/projekmmo/berita/article/indeks-syariah-malaysia-beri-markah-75.42peratus-kepada-diri-sendiri

[25] Malaysiakini (2015). Multaqa Alumni Al-Azhar ingin rintis perpaduan PAS dan UMNO. 17 Disember. http://www.malaysiakini.com/news/323698

[26] Mazuki, A. A. M., Mujani, W. K., Aziz, A., Rozali, E. A. (2013). Aplikasi Konsep Wasatiyyah Dalam Pembentukan Piagam Madinah. International Journal of West Asian Studies 1 EISSN: 2180-4788 5(2), pp. 1-5.

[27] Muhammad, A. (2016). Najib, Hadi sertai himpunan solidariti Rohingya. Malaysiakini. 4 Disember. http://www.malaysiakini.com/news/365120

[28] Muzaffar, C. (1986). Malaysia: Islamic Resurgence and the Question of Development. Sojourn: Journal of Social Issues in Southeast Asia, pp. 57-75

[29] Nakhleh, E. (2009). Political Islam AndIslamization Chapter 1: A Necessary Engagement. Princeton University Press

[30] Nasir, B. M. \& Ismail, N. K. (Ed.) (2011). Kepimpinan dan Kedudukan Ulama dalam Organisasi Parti Islam SeMalaysia (PAS). Prosiding Nadwah Ulama Nusantara (NUN) IV: Ulama Pemacu Transformasi Negara, pp. 116123.

[31] Nasr, S. H. (2003). Islam Religion, History and Civilization. Harper Collins e-book

[32] Nor, R. M. (2011). Sejarah Emas Perjuangan Islam di Malaysia. Kuala Lumpur: Jundi Resources

[33] Othman Lebar (2015). Penyelidikan Kualitatif: Pengenalan kepada Teori dan Metode. Tanjong Malim: Penerbit Universiti Pendidikan Sultan Idris

[34] Pandian, S. (2005). Legasi Mahathir. Kuala Lumpur: Utusan Publications \& Distributors Sdn. Bhd

[35] Perlembagaan PAS pindaan 2011

[36] Perlembagaan Persekutuan Malaysia 2010

[37] Rawa, M. Y. (2016). Adakah indeks syariah ukur isu 1MDB, derma? Malaysiakini. 28 Mac. http://www.malaysiakini.com/news/335627

[38] Razak, R. R. A. \& Zakariah, M. H. (2010). Islam Hadhari: apa dan kenapa. Jurnal Hadhari 3, pp 1-21

[39] Roshdi, M. S. M. (2011). Transisi Politik Dari negara Islam kepada Negara Berkebajikan Parti Islam Se-Malaysia (PAS): Cabaran dan Matlamat. Kertas Kerja The 6th ISDEV International Graduate Workshop (INGRAW 2011). Universiti Sains Malaysia, 11-12 Oktober

[40] Saat, N. (2015). Testing the Political Waters: PAS's Hudud Proposal and Its Impact. Institute of Southeast Asian Studies (ISEAS) 71(1), pp. 46-47

[41] Salleh, M. S. (2005). Islam Hadhari: dari perspektif pembangunan berteraskan Islam. Islam Hadhari 39, pp. 53-83.

[42] Syuib, M. S. (2007). Cetusan pendekatan Islam Hadhari bagi menangani ekstremisme Islam di Malaysia. Laporan Penyelidikan Geran Fakulti. Fakulti Pengajian Antarabangsa, Universiti Utara Malaysia

[43] UMNO Online (2016). Ahmad Zahid: RUU 355 bukan pintu belakang laksana hudud. 3 Disember. http://www.umno-online.my/2016/12/03/ruu-355-bukan-pintu-belakang-laksana-hudud-ahmad-zahid/

[44] Welsh, B. \& Chin, J. U. (Ed.) (2004). Bangkit: Tempoh Pentadbiran Ahmad Badawi di Malaysia (Ahmad, N. A., Trans.). Petaling Jaya: Strategic Information Research Development (SIRD)

[45] Yatim, N. (2011). PAS sedia 10 agenda. Sinar Harian. 11 Disember. http://www.sinarharian.com.my/politik/passedia-10-agenda-1.11771?fb_comment_id=10150618162604616_24026225\#f383d3aed1af04

[46] Zain, I. M. (2015). MB Kelantan selesai bentang pindaan enakmen hudud, ADUN UMNO sokong. Astro Awani. $18 \mathrm{Mac}$ 2015. http://www.astroawani.com/berita-politik/mb-kelantan-selesai-bentang-pindaan-enakmen-hududadun-umno-sokong-55895

[47] Zain, M. I. M. (2014). From Islamist to Muslim Democrat: The Present Phenomenon of Muslim Politics in Malaysia. International Journal of Islamic Thought 6 (12), pp. 37-45

[48] Zulkifli, Z. (2016). Presiden PAS: Terima kasih kerajaan. Malaysiakini. 26 Mei. https://www.malaysiakini.com/news/343063 